\title{
Study Based on Bridge Health Monitoring System on Multihazard Load Combinations of Earthquake and Truck Loads for Bridge Design in the Southeast Coastal Areas of China
}

\author{
Dezhang Sun, ${ }^{1}$ Bin Chen, ${ }^{2}$ and Baitao Sun ${ }^{1}$ \\ ${ }^{1}$ Institute of Engineering Mechanics, China Earthquake Administration, Harbin 150080, China \\ ${ }^{2}$ College of Civil Engineering and Architecture, Zhejiang University, Hangzhou 310058, China \\ Correspondence should be addressed to Bin Chen; jeetchen_123@hotmail.com
}

Received 8 August 2014; Accepted 1 October 2014

Academic Editor: Bo Chen

Copyright ( $\odot 2015$ Dezhang Sun et al. This is an open access article distributed under the Creative Commons Attribution License, which permits unrestricted use, distribution, and reproduction in any medium, provided the original work is properly cited.

Similar to American LRFD Bridge Design Specifications, the current Chinese bridge design code is fully calibrated against gravity load and live load. Earthquake load is generally considered alone and has its own methodology, however, which is not covered in the code in a consistent probability-based fashion. Earthquake load and truck load are the main loads considered in the basis of bridge design in more than $70 \%$ of seismic areas in China. They are random processes, and their combination is the main subject of this paper. Seismic characteristics of southeast coastal areas of China are discussed and an earthquake probability curve is calculated through seismic risk analysis. Using measured truck load data from a Bridge Health Monitoring System, the multimodal characteristics of truck load are analyzed and a probability model for a time interval $t$ is obtained by fitting results and reliability theory. Then, a methodology is presented to combine earthquake load and truck load on a probabilistic basis. To illustrate this method, truck load and earthquake load combinations are used. Results conceptually illustrate that truck load and earthquake load are not dominant in southeast coastal areas of China, but the effect of their combination is. This methodology quantitatively demonstrates that the design is controlled by truck load in most ranges; that is, truck load is more important to bridge design in the region.

\section{Introduction}

In the current bridge design specifications of China [1] a typical bridge is designed for 100 years' service life and the design limit states are only fully calibrated for dead and live loads. Consideration of earthquake load has its own unique approach, principally because data and statistics are rare. Truck load data are old and may not suit the current situation, and they therefore need to be updated. This fact makes it difficult to properly consider both truck load and earthquake load in a consistent fashion. A research project is currently being carried out to establish a methodology to systematically combine truck load and earthquake load. Principle emphasis is given to establishing the proper "demand." In order to pursue the demand side of bridge design specifications, there are numerical challenges that must be overcome in addition to the fact that very limited historical data are available. Truck load and earthquake load are time-variant random processes. Truck load occurs once in a typical time span of minutes or seconds on a common bridge, while earthquake load occurs once in a typical time span of years or decades. Furthermore, there is no evidence that the occurrence of earthquake loads follows normal distributions. Fortunately, many bridge health monitoring systems (BHMS) have been established, which provide a convenient way to get useful data for this research [2].

To overcome the challenges, many efforts [3-9] have been made in the past decades. However, because numbers of assumptions have to be made in each model, no general conclusions can be drawn about satisfactory approach to deal with load combination of earthquake load and truck load. In more recent papers, a methodology is proposed by Liang and Lee $[10,11]$; however, its accuracy is yet to be substantiated. 
One objective of this paper is to describe a methodology to handle truck load and earthquake load combinations. Earthquake load is modeled using seismic risk analysis. Truck load is modeled using Stationary Poisson processes based on the BHMS and statistical analysis. Two numerical examples of truck load and earthquake load combinations are used to illustrate the methodology.

\section{Earthquake Load}

A number of variables describe the effects that earthquakes have on bridges, such as the intensity of acceleration, the rate of earthquake occurrences, the natural period of the bridge, the seismic response coefficient, and the response modification factor. In order to explain the methodology of load combinations, only the intensity of acceleration and the rate of occurrence are chosen as the main variables.

Based on the Poisson process assumption, the probability of exceedance $\left(P_{e}\right)$ in a given exposure time $\left(T_{e}\right)$ is related to the annual probability of exceedance $(\lambda)$ by [12],

$$
P_{e}=1-e^{-\lambda \cdot T_{e}} .
$$

Because the number of earthquakes varies widely from site to site, they are converted to Peak ground acceleration (PGA) and the return period curve $\left(T_{R}=1 / \lambda, T_{R}\right.$ is return period). The cumulative probability of an earthquake in time $T$ can be written as

$$
P=e^{-T / T_{R}} \text {. }
$$

The PGA and frequency of exceedance curve can be obtained from U.S. Geological Survey (USGS) mapping in the United States but cannot be obtained in China. Therefore, seismic risk analysis is used to calculate earthquake probability curve. The procedures are presented just as follows.

For more than one potential seismic source zone, suppose the parameters of the earthquake are random distributions and the probability over 1 year is a stable Poisson process. Based on the total probability theorem, the probability of exceeding a given earthquake intensity $S_{0}$ in one site can be expressed by (3), by considering the uncertainties of occurrence and the upper limit magnitude:

$$
P_{t}\left(S>S_{0}\right)=1-\prod_{k=1}^{K} \sum_{i=1}^{I} W_{r, k}^{(i)} \exp \left[-\sum_{j=1}^{J} v_{k, j}^{(i)} \cdot P_{k}^{(j)} W_{u, k}^{(j)} \cdot t\right],
$$

where $P_{k}^{(i)}$ is the probability of the $j$ th upper limit magnitude exceeding a given earthquake intensity $S_{0}$ in potential seismic source $k, v_{k, j}^{(i)}$ is the $i$ th year occurrence probability of the $j$ th upper limit magnitude in potential seismic source $k, W_{r, k}^{(i)}$ is the weight of the $i$ th year occurrence probability in potential seismic source $k$, and $W_{u, k}^{(j)}$ is the weight of the $j$ th upper limit magnitude in potential seismic source $k$.

The earthquake intensity could be acceleration, velocity, or displacement. For acceleration, $S=\ln a$ ( $S$ is earthquake intensity; $a$ is acceleration).
Because of the uncertainties of direction impact of potential seismic source zones, for $t=1$ year, the probability of exceedance is

$$
P_{1}\left(S>S_{0}\right)=\sum_{k=1}^{K} \sum_{i=1}^{I} \sum_{j=1}^{J} v_{k}^{(i)} P_{k}^{(j)} W_{r, k}^{(i)} W_{u, k}^{(j)}
$$

where $P_{k}^{(j)}$ is the conditional probability of the $j$ th upper limit magnitude.

For disperse potential seismic source areas, the probability of the $j$ th upper limit magnitude can be expressed as

$$
P_{k}^{(j)}\left(S>\left.S_{0}\right|_{M_{u, k}}\right)=\frac{\sum_{k=1}^{K} P_{\xi}^{(j)}\left(S>\left.S_{0}\right|_{R}\right) \Delta A_{\xi}}{A_{k}},
$$

where $A_{k}$ is the area of the potential seismic source $k ; \Delta A_{\xi}$ is the area of zone $\mathbf{x}$. If the occurrence probability of 1 year is divided by the weights in each upper limit magnitude of potential seismic source zone, the exceedance probability of the $j$ th upper limit magnitude of potential seismic source $k$ can be given as

$$
\begin{aligned}
P_{\xi}^{(j)}= & \frac{\sum_{n} \xi_{n}\left\{K_{r}\left[\Phi_{n+1}^{\prime \prime}-\Phi_{n}^{\prime \prime}\right]+\left[e^{-\beta M_{n}^{(j)}} \Phi_{n}^{\prime}-e^{-\beta M_{n+1}^{(j)}} \Phi_{n+1}^{\prime}\right]\right\}}{\sum \xi_{m}\left[e^{-\beta M_{n}^{(j)}}-e^{-\beta M_{n+1}^{(j)}}\right]} \\
& +\Phi_{0} .
\end{aligned}
$$

According to the seismic belt materials and reports, the southeast coastal area of China has two I degree seismic areas, namely, the South China seismic area and the South China Sea seismic area. The seismic belt of southeast coastal areas of China is located south of the middle Yangtze River seismic belt, bordering on the seismic region of the Tibetan Plateau on the west, and includes Kwangtung province, Hainan province, most of Fujian and Guangxi provinces, and part of Yunnan, Guizhou, and Jiangxi provinces. Crustal thickness ranges between 28 and $40 \mathrm{~km}$, gradually increasing from the southeast coastal area of China to the northwest mountains. An internal secondary elliptical gravity anomaly is relatively developed in the earthquake zones. There are no obvious banded anomalies except the gravity gradient zones of southeast coastal areas and Wuling Mountain. In the zones, magnetic anomalies change gently and there are no larger banded anomalies. Because the southeast coastal areas of China are in the same seismic belt and most of the areas in the zone have a PGA seismic fortification level of $0.1 \mathrm{~g}$, Shenzhen city is then used for the basic earthquake probability calculation and comparison in this paper. The South China belt is shown in Figure 1. From Figure 1, it can be seen that there are many higher than Ms 6.0 earthquakes in the southeast coastal areas of China present in the seismic analysis. Earthquake load is still the main load considered for bridge design in these areas.

Based on (3) to (6), the annual exceedance probability of Shenzhen is shown in Figure 2. 

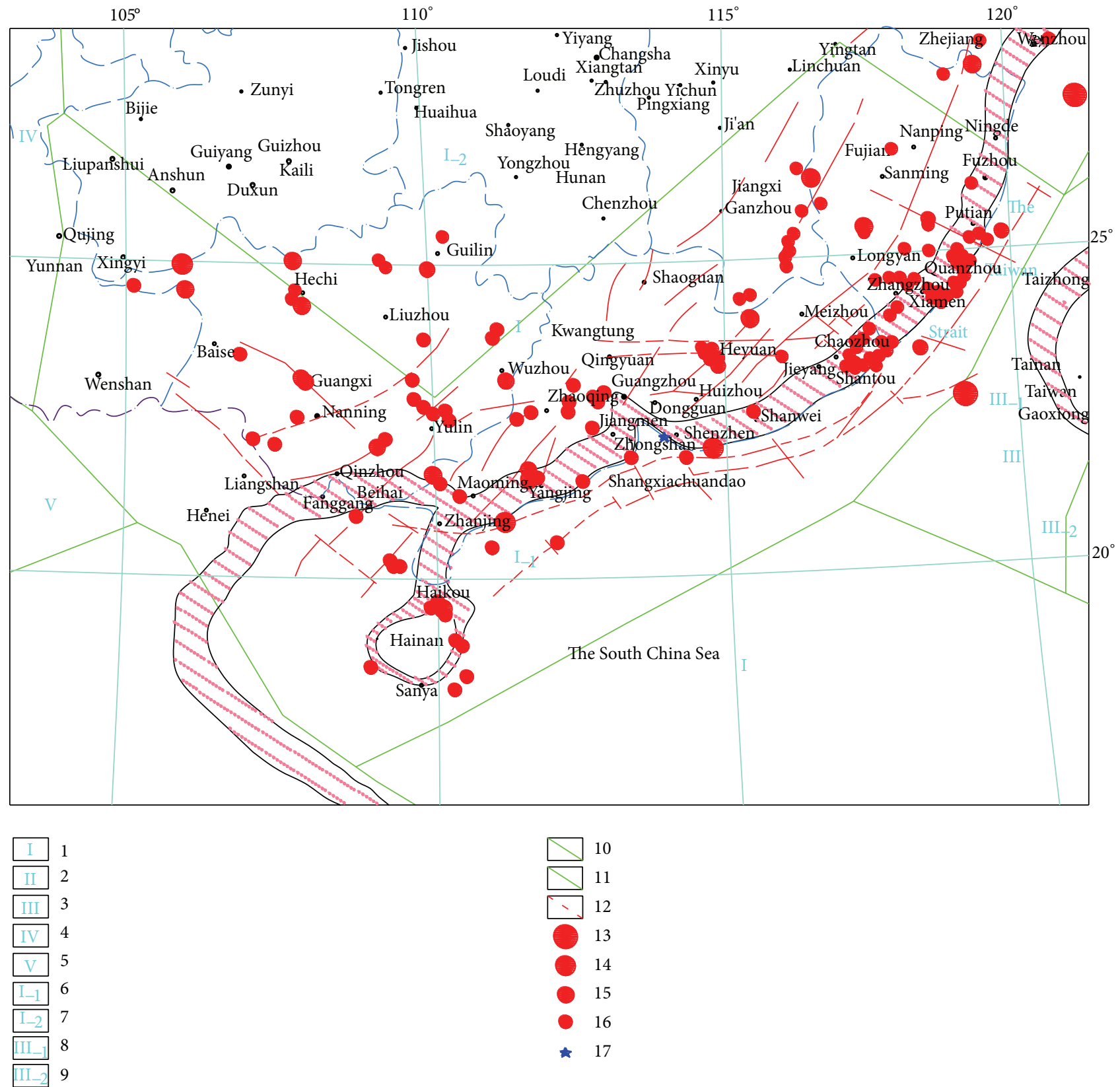

Figure 1: The South China belt. (1) The seismic area of South China. (2) The seismic area of South China Sea. (3) The seismic area of Taiwan. (4) The earthquake subregion of middle of Qinghai-Tibet Plateau. (5) The earthquake subregion of south of Qinghai-Tibet Plateau. (6) The southeast costal seismic belt (South China coastal seismic belt). (7) The seismic zone in the middle reach of Yangtze River. (8) Seismic area of the west of Taiwan. (9) Seismic area of the east of Taiwan. (10) Boundaries of seismic zone. (11) Boundaries of seismic belt. (12) South China coastal seismic rupture. (13) Epicenter of Ms 7 and above. (14) Epicenter of Ms 6.0-6.9. (15) Epicenter of Ms 5.0-5.9. (16) Epicenter of Ms 4.7-4.9. (17) Calculation site.

Assume that the probability density of earthquake load intensity in time $T$ follows a distribution defined as $f_{T}(y)$, where $y$ is a variable of PGA intensity. Based on the Poisson process assumptions, the cumulative probability function $F_{t}(y)$ over interval $t$ can be obtained using the following:

$$
F_{t}(y)=\left[F_{T}(y)\right]^{t / T} \text {. }
$$

The probability density function can then be derived as

$$
f_{t}(y)=\frac{\partial F_{t}(y)}{\partial y}=\frac{t}{T} \cdot\left[F_{T}(y)\right]^{(t / T-1)} \cdot f_{T}(y) .
$$

Note that $t$ and $T$ should have the same dimension. 


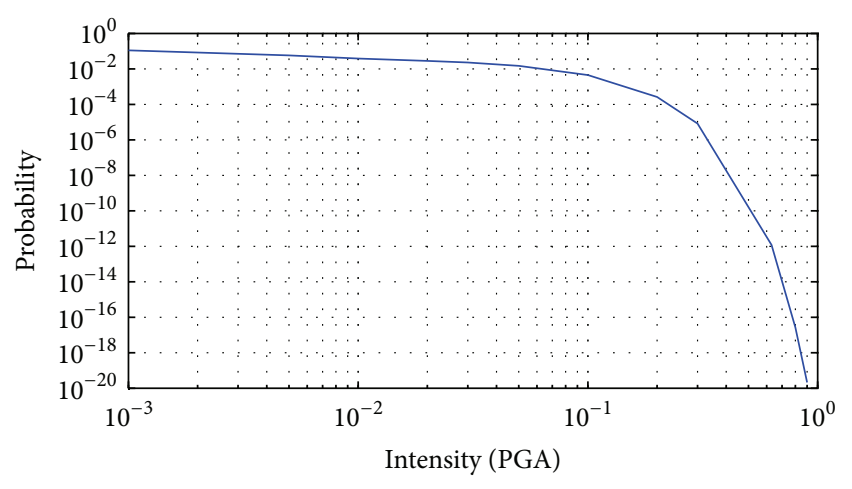

FIgURE 2: Annual exceedance probability of PGA.

\section{Truck Load}

Studies on truck load have been difficult historically, principally because weighing equipment was lacking and the data are correspondingly rare $[13,14]$. Fortunately, the installation of BHMS is required on newly built long-span bridges, including the weighing-in-motion (WIM) system [15-17]. Time, gross weight, axle weight, wheel base, velocity, and so forth are measured and collected. The probability model of truck load can be obtained through statistical analysis.

Nowak [18] indicated that at a specific site heavy trucks may have an average number of 1000, which is also discussed by Ghosn. Moses [19] suggested heavy trucks follow a normal distribution with a mean of $300 \mathrm{kN}$ and a standard deviation of $80 \mathrm{kN}$ (coefficient of variable, COV $=26.5 \%$ ). Zhao and Tabatabai [20] discussed the local standard vehicle model, using data from about six million vehicles in Washington, which can be used as a reference for a truck load model. In this paper, the truck load model is obtained through data mining from measured WIM data from three bridge sites in Hangzhou, Xiamen, and Shenzhen (Figure 3). Truck load data of 5 axles and more in the three sites are filtered and selected. Through WIM data analysis, truck load probability characteristics of Hangzhou, Xiamen, and Shenzhen are similar, even the shape of truck load probability curves. Considering the three sites have very similar traffic flow, almost equal to 1.0, truck load probability curve of Shenzhen City is used for analysis and validity of subsequent case studies. Truck load probability curve is shown in Figures 4 and 5 . The fitted curve is obtained using normal distribution, whose mean value is $294.9 \mathrm{kN}$, and the coefficient of variance is $37.4 \%$.

For a typical bridge, the truck load will consist of a varying number of trucks on the bridge. The probability function for such a bridge can be obtained using following analysis. Assume $A$ is a set consisting of the elements $A_{1}, A_{2}, \ldots, A_{m}$, which present $m$ events, and the probability of $A$ is $P(A)$, while $B$ is a set consisting of the elements $B_{1}, B_{2}, \ldots, B_{n}$, which present $n$ events, and the probability of $B$ is $P(B)$; so the probability $P(A+B)$ presents the probability of intensity $(A+B)$. Then $P(A+B)$ can be calculated by

$$
P_{A+B}(k)=\sum_{i} P_{A}(i) \cdot P_{B}(k+1-i) .
$$

Note that the length of $P(A)$ is $m$ and the length of $P(B)$ is $n$. The sum is over all the values of $i$ which lead to legal subscripts for $A(i)$ and $B(k+1-i)$, where $k$ is the $k$ th $(A+B)(k)$, $i=\max (1, k+1-n): \min (k, m)$. Equation (9) reflects the probability of combining two sets, and when it comes to a series of sets $\Phi=\Phi_{1}+\Phi_{2}+\cdots+\Phi_{N}$, (9) can be extended to $N$ dimensions,

$$
\begin{aligned}
P_{\Phi}\left(\phi_{1}+\phi_{2}+\cdots+\phi_{N}\right) \\
=\sum\left(\cdots\left(\sum\left(\sum P_{\Phi_{1}}\left(\phi_{1}\right) \cdot P_{\Phi_{2}}\left(\phi_{2}\right)\right) \cdot P_{\Phi_{3}}\left(\phi_{3}\right)\right) \cdots\right) \\
\quad \cdot P_{\Phi_{N}}\left(\phi_{N}\right),
\end{aligned}
$$

where $\Phi_{i}$ in (10) is the $i$ th set of event and $P_{\Phi_{i}}\left(\phi_{i}\right)$ is the probability of set $\Phi_{i}$.

Based on total probability theory and Poisson processes, the truck load intensity function for an interval $t$ can be calculated using the following:

$$
F_{\Phi}(\phi)_{t}=P_{\Phi_{0}}+\sum_{N} P_{\Phi_{1}+\Phi_{2}+\cdots \Phi_{N}} \cdot p(N)
$$

where $P_{\Phi_{0}}$ is the probability with no truck passing on the bridge; $N=1,2, \ldots$ maximum number of trucks. $P_{\Phi_{1}+\Phi_{2}+\cdots \Phi_{N}}$ is the probability of varying number of trucks passing the bridge; $p(N)$ is the probability of occurrence of $N$ trucks on the bridge.

\section{Model of Combination}

The intensity of dead load is usually defined as a time independent variable, and that of truck load is a time dependent variable, both of whom follow normal distributions $[5,8$, 18]. In this paper, a normal distribution is used for dead load, which is considered to maintain more or less the same magnitude, such that it can be treated as a random time independent variable.

As mentioned above, earthquake load and time-variable truck load are assumed to be Poisson processes, each with same distribution and time duration. Based on these assumptions, as mentioned earlier load processes can be converted to a small $t$ interval, in which loads can be combined. The objective of time-variable combination is to find the maximum value of different random variables, namely, the combined value $X=X_{1}+X_{2}+\cdots+X_{n}$, with an interval $t$ and maximum value $X_{\max , T}$, in a time $T . n$ is the number of loads, $X$ is the intensity of combined load, and $X_{i}$ is the load intensity of the $i$ th load. The maximum value of $X$ in the lifetime of the bridge can be expressed as

$$
X_{\max , T}=\max _{T}\left[X_{1}+X_{2}+\cdots+X_{n}\right]_{t} .
$$

To simplify the discussion, the number of loads is taken as two, the problem being reduced to the prediction of $X_{1,2}=$ $X_{1}+X_{2}$, where $X_{1,2}$ is the intensity of the union of $X_{1}$ and $X_{2}$. Assume that $f_{1}(x)$ and $f_{2}(x)$ are the probability density functions of $X_{1}$ and $X_{2}$ in the interval $t$ and $F_{1}(x)$ and $F_{2}(x)$ are the cumulative probability functions of $X_{1}$ and $X_{2}$ in the 


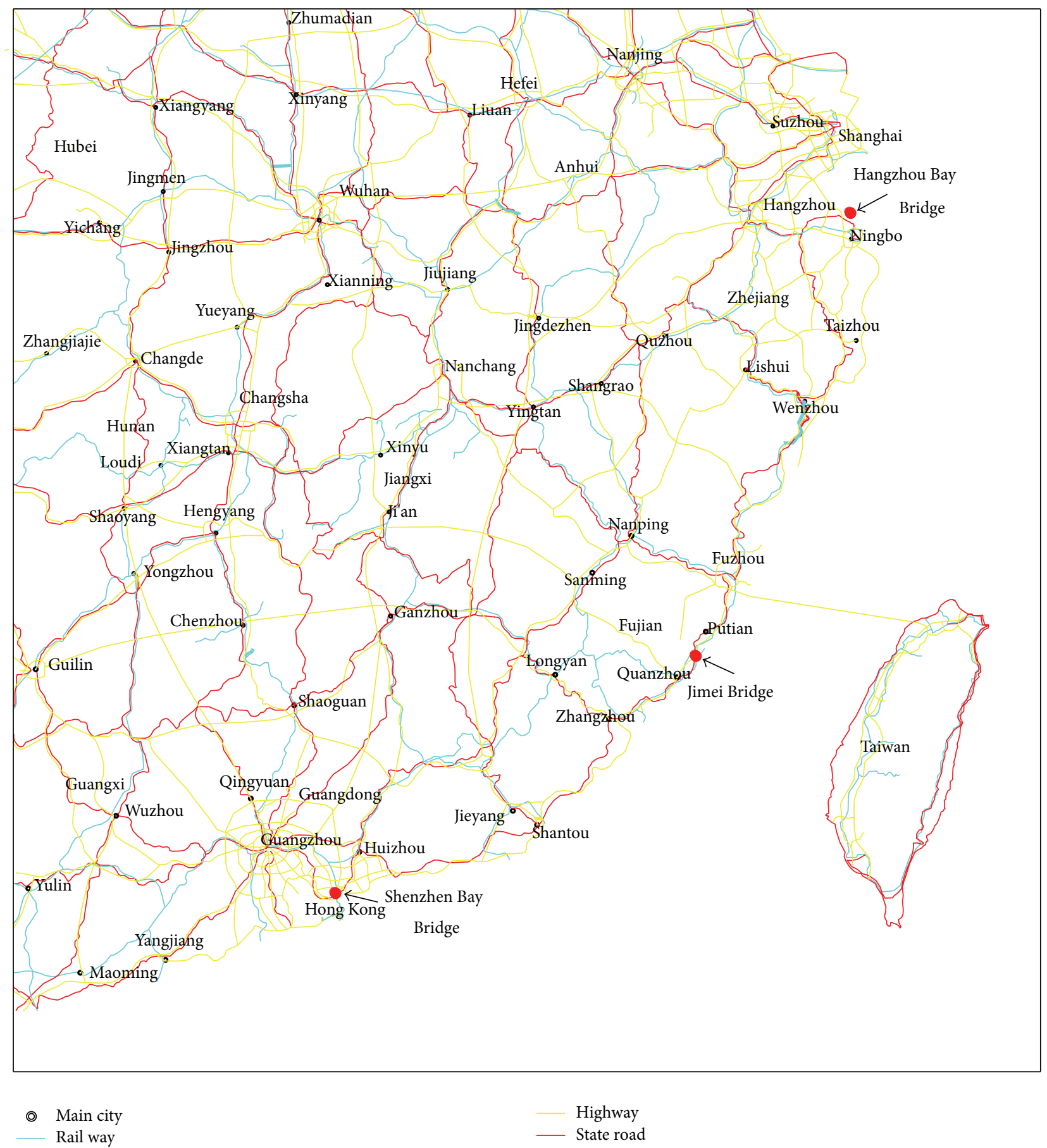

FIGURE 3: Layout of monitoring sites.

interval t. $f_{X_{1,2}}(x)$ and $F_{X_{1,2}}(x)$ are the probability density function and cumulative probability function of $X_{1,2}$. The maximum value of combination in the entire bridge service life is defined as $X_{1,2 \max , T}$, which is defined as

$$
X_{1,2 \max , T}=\max _{T}\left[X_{1}+X_{2}\right]_{t} .
$$

The probability density of the combined loads $X$ can be obtained using the convolution integral:

$$
f_{X_{1,2}}(x)=f_{1} * f_{2}=\int_{-\infty}^{+\infty} f_{1}(\tau) \cdot f_{2}(x-\tau) d \tau,
$$

where "*" is used as convolution symbol. 


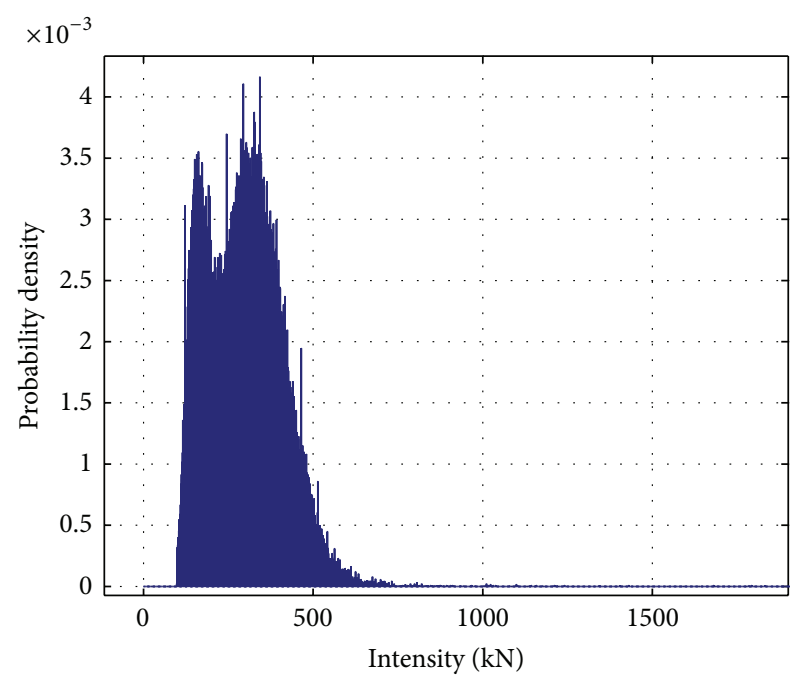

FIgURE 4: Histogram of the monitoring sites.

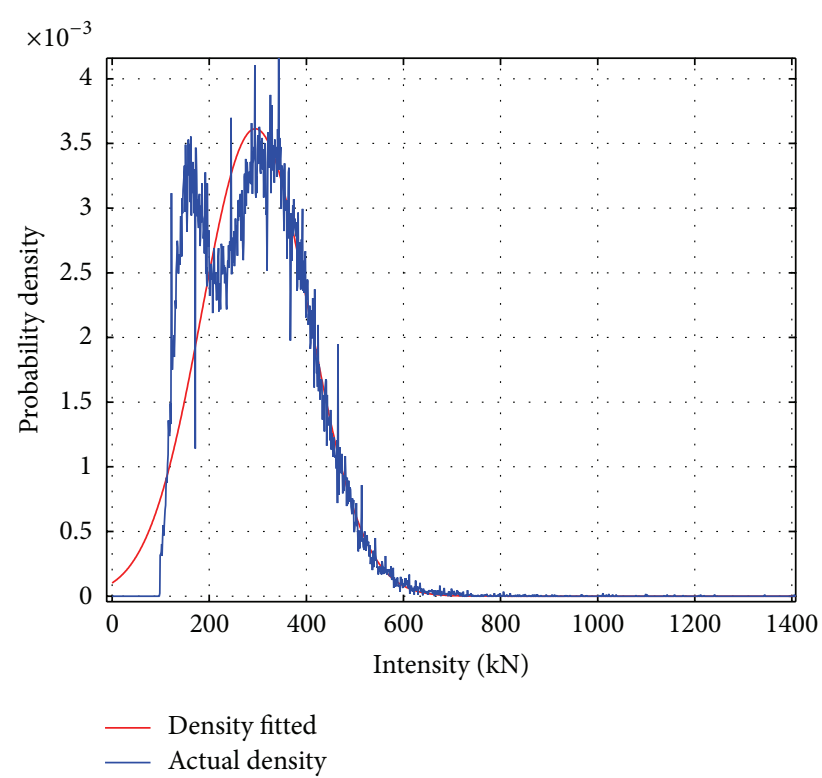

Figure 5: Curve fitting of truck load density.

Dirac Delta function is introduced to deal with the characteristics of $X$ and $Y$ in small $t$ interval:

$$
\delta(x)= \begin{cases}+\infty, & x=0 \\ 0, & x \neq 0\end{cases}
$$

Therefore, the probability density can be illustrated as

$$
f_{i}(x)=P_{X_{i, 0}} \delta(x)+f_{i}^{\prime}(x), \quad i=1,2 .
$$

Note that $P_{X_{i, 0}}$ is the probabilities of $X_{i}(i=1,2)$ in its "zero points"; namely, the events do not happen (e.g., the maximum trucks on the bridge are $8 ; P_{X_{i, 0}}$ is the probability of no trucks on the bridge). $f_{i}^{\prime}(x)$ is its probability density functions without "zero points." Then, the cumulative probability functions of $X_{1}$ and $X_{2}$ can be calculated through

$$
\begin{aligned}
F_{i}(x) & =P_{X_{i, 0}} \int_{-\infty}^{x} \delta(\tau) d \tau+\int_{-\infty}^{x} f_{i}^{\prime}(x) d \tau \\
& =P_{X_{i, 0}}+\int_{-\infty}^{x} f_{i}^{\prime}(x) d \tau,
\end{aligned}
$$

where $i=1,2$.

Based on (16) and (17), the probability density of $X$ then can be grouped as

$$
\begin{aligned}
& f_{X_{1,2}}(x) \\
& =\int_{-\infty}^{+\infty}\left[P_{X_{1,0}} \delta(\tau)+f_{1}^{\prime}(\tau)\right] \\
& \quad \times\left[P_{X_{2,0}} \delta(x-\tau)+f_{2}^{\prime}(x-\tau)\right] d \tau \\
& =\int_{-\infty}^{+\infty}\left\{\left[P_{X_{1,0}} P_{X_{2,0}} \delta(\tau) \delta(x-\tau)\right]\right. \\
& \quad+\left[P_{X_{1,0}} \delta(x) f_{2}^{\prime}(x-\tau)\right]+\left[P_{X_{2,0}} \delta(x-\tau) f_{1}^{\prime}(\tau)\right] \\
& \left.\quad+\left[f_{1}^{\prime}(\tau) f_{2}^{\prime}(x-\tau)\right]\right\} d \tau \\
& =P_{X_{1,0}} P_{X_{2,0}} \delta(x)+P_{X_{1,0}} f_{2}^{\prime}(x)+P_{X_{2,0}} f_{1}^{\prime}(x) \\
& +\int_{-\infty}^{+\infty} f_{1}^{\prime}(\tau) f_{2}^{\prime}(x-\tau) d \tau,
\end{aligned}
$$

where based on the characteristic of Dirac Delta function, which is $\int_{-\infty}^{+\infty} \delta(x) d x=1,(18)$ can be converted to cumulative probability function. Assume the cumulative probability function of $F_{X_{1,2}}(x)$; then

$$
\begin{aligned}
F_{X_{1,2}}(x)= & \int_{-\infty}^{x} f_{X_{1,2}}(x) d x \\
= & P_{X_{1,0}} P_{X_{2,0}}+P_{X_{1,0}} F_{2}^{\prime}(x)+P_{X_{2,0}} F_{1}^{\prime}(x) \\
& +\int_{-\infty}^{+\infty} F_{1}^{\prime}(\tau) f_{2}^{\prime}(x-\tau) d \tau .
\end{aligned}
$$

From (19), it is clear that the combined load probability consists of four parts: events $X_{1}$ and $X_{2}$ are not happening; event $X_{1}$ is happening while $X_{2}$ is not happening; event $X_{1}$ is not happening while $X_{2}$ is happening; and $X_{1}, X_{2}$ are both happening.

To further simplify the discussion without losing generality, the probability of two loads occurring simultaneously is neglected. Thus (19) is simplifying to

$$
\begin{aligned}
F_{X_{1,2}}(x) & =\int_{-\infty}^{x} f_{X_{1,2}}(x) d x \\
& \approx P_{X_{1,0}} P_{X_{2,0}}+P_{X_{1,0}} F_{2}^{\prime}(x)+P_{X_{2,0}} F_{1}^{\prime}(x) .
\end{aligned}
$$


Then the cumulative probability function, $F_{X_{1,2, \max , T}}(x)$, of maximum value of load combinations, $X_{1,2, \max , T}(x)$, in time $T$ can be obtained,

$$
F_{X_{1,2, \max , T}}(x)=\left[F_{X_{1,2}}(x)_{t}\right]^{T / t} .
$$

When the number of loads is more than two and these loads apply to bridge directly while satisfying Poisson process, (14) can be extended to $n$ dimensions. Assume $f_{1}, f_{2}, \ldots, f_{n}$ are the probability densities functions of $X_{1}, X_{2}, \ldots, X_{n} ; F_{1}, F_{2}, \ldots, F_{n}$ are the cumulative probability functions of $X_{1}, X_{2}, \ldots, X_{n} ; f_{1}^{\prime}, f_{2}^{\prime}, \ldots, f_{n}^{\prime}$ are the probability density functions of $X_{1}, X_{2}, \ldots, X_{n}$ without "zero" points; $f_{X}(x)$ and $F_{X}(x)$ are the probability density function and cumulative probability function. Then the probability density function is deduced as

$$
f_{X}(x)=f_{1}(x) * f_{2}(x) * \cdots * f_{n}(x),
$$

where the cumulative probability $F_{X, \max }(x)$, similar to that given by (19), is

$$
\begin{aligned}
F_{X}(x) & =\int_{-\infty}^{x} f_{X}(x) d x \\
& =\int_{-\infty}^{x} f_{1}(x) * f_{2}(x) * \cdots * f_{n}(x) d x .
\end{aligned}
$$

Equation (23) can account for load combinations of all loads, which satisfy the first three assumptions. If more than two events occurring simultaneously can be neglected, (23) reduces to

$$
\begin{aligned}
F_{X}(x)= & \int_{-\infty}^{x} f_{X}(x) d x \\
\approx & P_{X_{1,0}} P_{X_{2,0}} \cdots P_{X_{n, 0}}+F_{1}^{\prime} P_{X_{2,0}} \cdots P_{X_{n, 0}} \\
& +\cdots+P_{X_{1,0}} P_{X_{2,0}} \cdots P_{X_{n-1,0}} F_{n}^{\prime} .
\end{aligned}
$$

Then the maximum value of $X$ in time $T$ can be obtained by

$$
F_{X_{\max , T}}(x)=\left[F_{X}(x)_{t}\right]^{T / t},
$$

where $F_{X}(x)_{t}$ is $F_{X}(x)$ in $t$ interval; $F_{X_{\max , T}}(x)$ is the cumulative probability function of maximum value of $X$ in time $T$.

Although in our study emphasis is given to formulate the "demand" to establish load combinations, all events must address a capacity issue of the bridge. For example, the earthquake load and truck load combination on a bridge column can either consider the vertical load or the column base shear load. Theoretically, (23) can deal with most load combinations, but as more loads are considered, a more conservative design will be adopted. Based on the methodology and assumptions described above, the maximum load can be combined and the procedures are summarized as follows:

(1) determine truck load and earthquake load distributions over a particular period;

(2) using Poisson processes, convert earthquake load and truck load distributions over a particular period to a sufficiently small interval $t$;

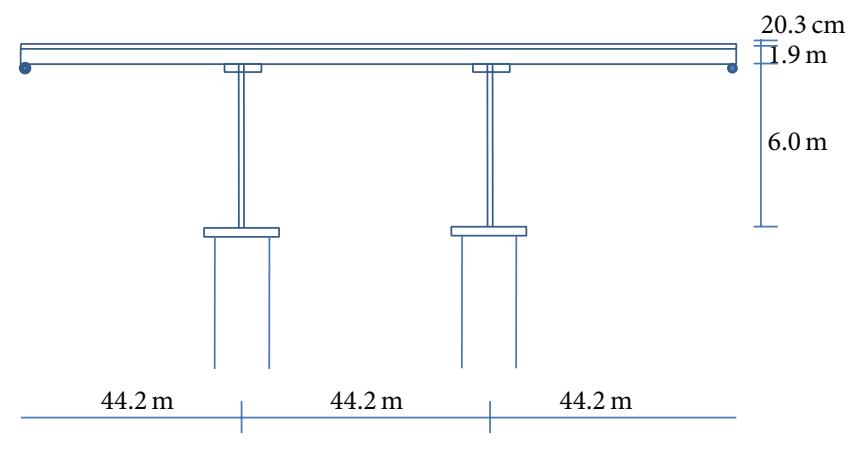

FIGURE 6: Longitudinal profile of the typical bridge.

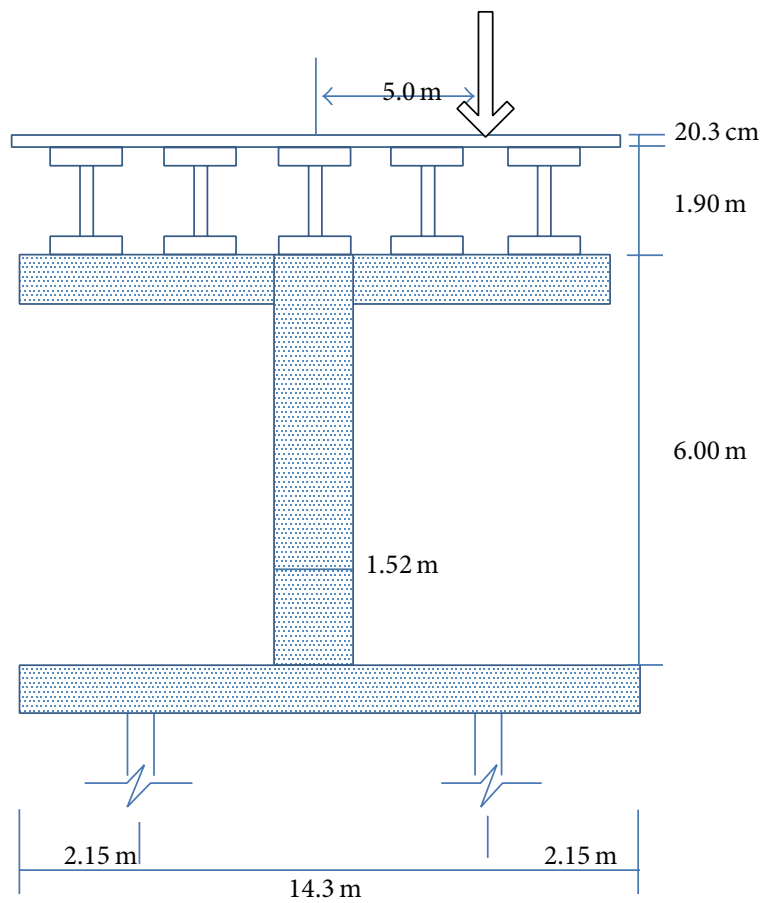

FIGURE 7: Transverse profile of the typical bridge.

(3) using (23), earthquake and truck load combinations over an interval $t$ can be obtained;

(4) using (25), the load combinations over an interval $t$ can be converted to the bridge service life interval $T$.

\section{Numerical Examples}

Example 1. Using the method of load combination described in the preceding section, a simple example of horizontal load combination is presented here. Profiles of the typical bridge are shown in Figures 6 and 7. The weight of the superstructure at each column is 538 tons, the eccentricity of truck load is 5.0 meters, and the effects of soil and secondary effects of gravity are ignored. Furthermore, it is assumed that the maximum number of trucks on one lane is two. The results are given in Figures $8,9,10,11,12,13$, and 14 . The interval $t$ is 10 seconds, and the average daily truck traffic (ADTT) is about 1947. 


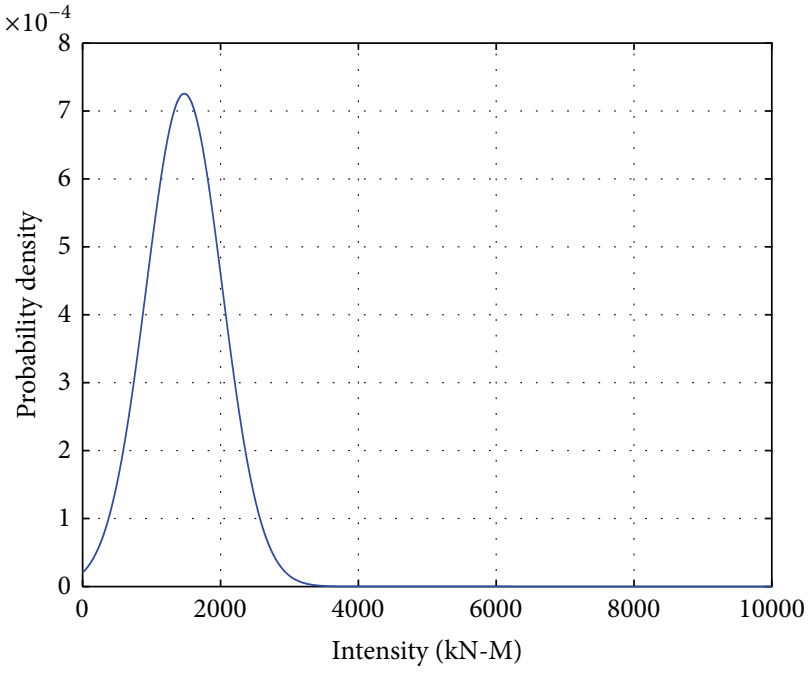

(a)

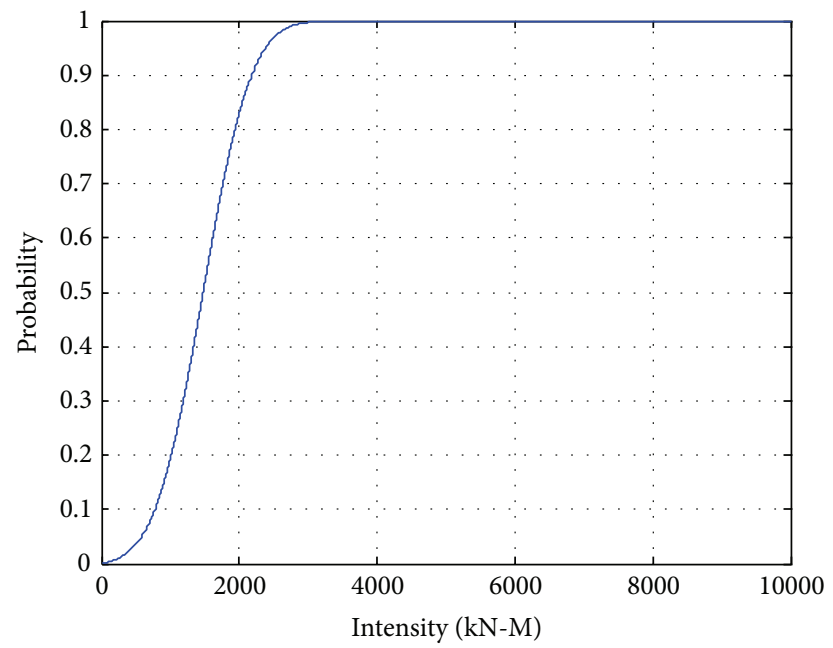

(b)

Figure 8: Probability curve of each truck load effect.

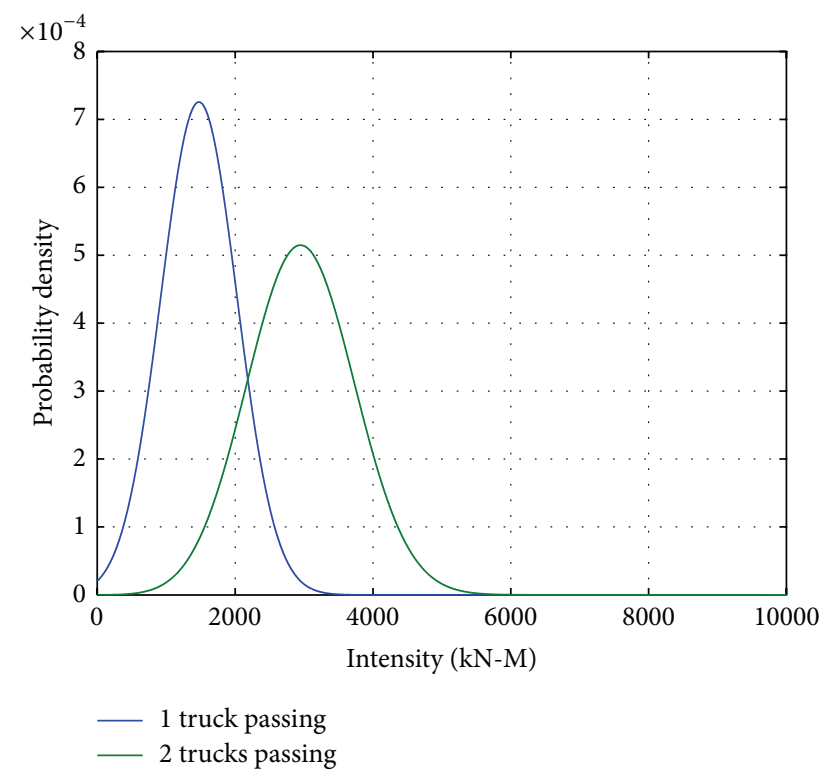

FIGURE 9: Truck load probability density curve for varied number of trucks.

Truck and earthquake load effects are the base moment caused by trucks and earthquakes, respectively. Figure 8 shows the probability curves of each truck load effect, which has a similar shape to truck load. Figure 9 shows the truck load probability density curve for varied numbers of trucks. From Figure 10 we can see that over the interval $t$ the probability of no truck on the bridge is much larger than the other number of trucks passing. Figure 11 shows the combined probability curves for truck load over an earthquake load duration, which indicate that the truck load over an earthquake load duration is larger than each truck load.

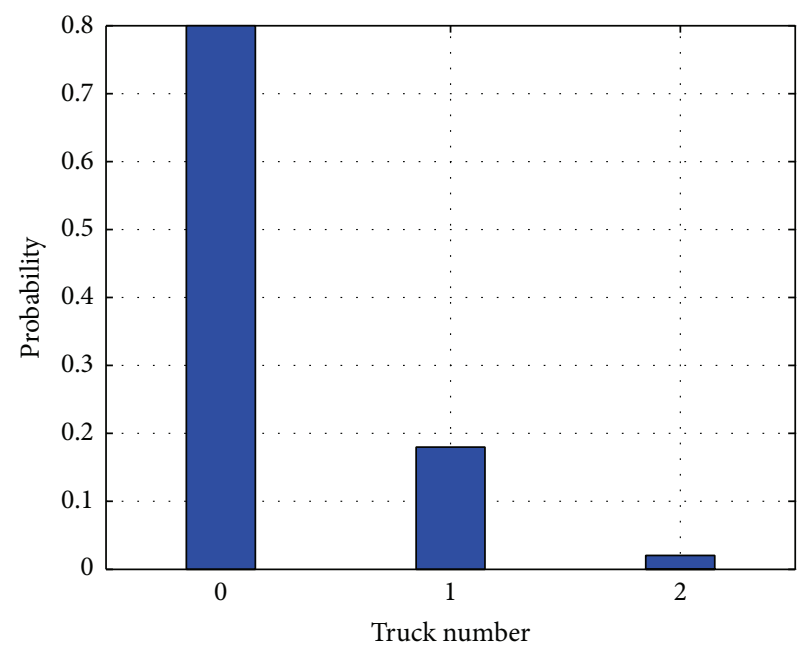

FIGURe 10: Probability of passing truck number simultaneously in $t$ interval on the bridge.

From the results shown in Figure 13, it can be seen that curve $C$ and curve $A$ have a similar shape and curve $C$ is displaced to the right. This means that mode and mean value of the truck and earthquake load combination in this example is larger than those of truck load and also illustrates that truck load is more important to bridge design in this area. From Figure 14, we can see more clearly that over most ranges truck load is larger than earthquake load. Because the truck load has a smaller tail, their combination in the tail is close to the earthquake load. Curve D of loads combined directly over 100 years is further away from curve $C$, which means the combinations of truck load and earthquake load directly over 100 years give a much larger value, and it is not suggested that the bridge design uses the curve $\mathrm{D}$ method. 


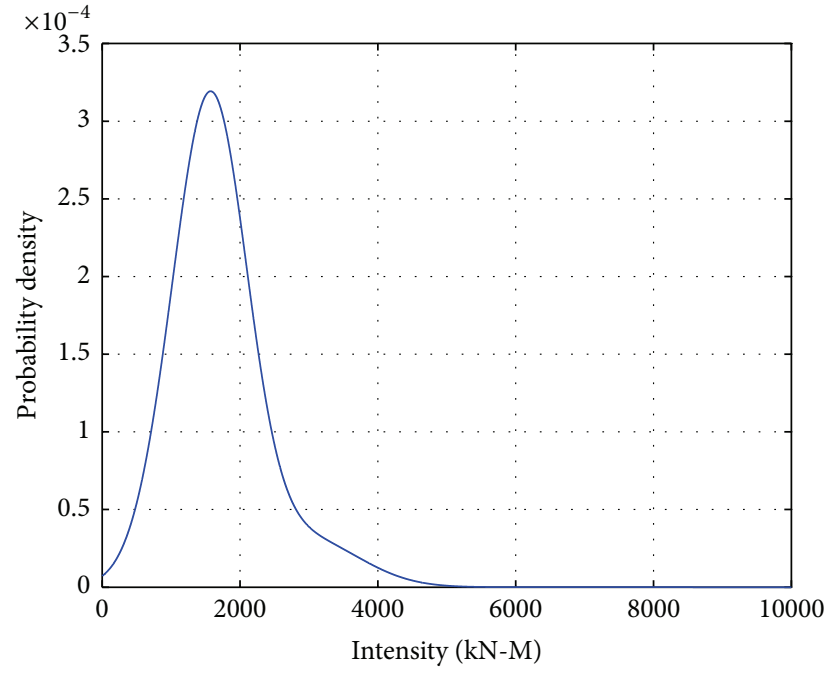

(a)

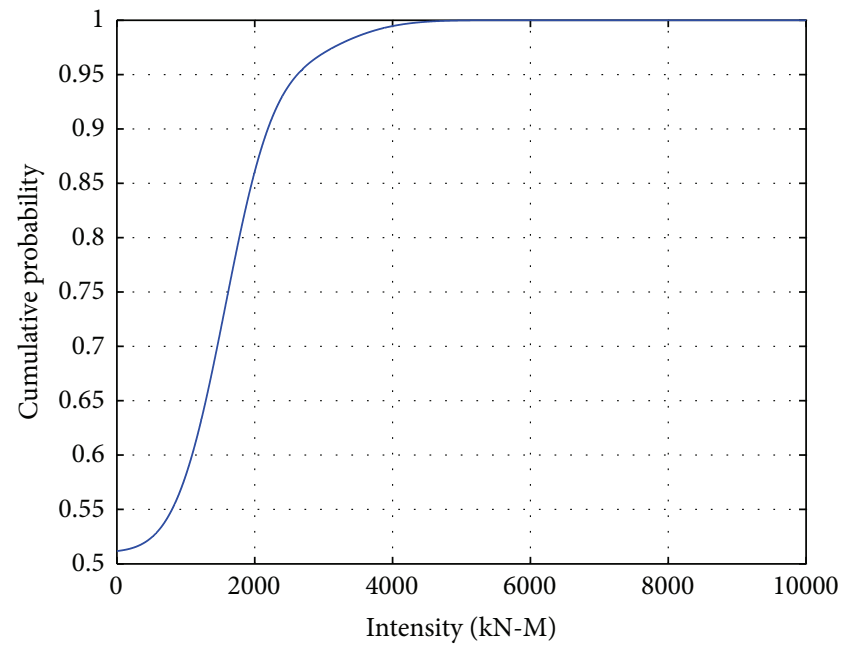

(b)

FIGURE 11: Combined probability curves for truck load in earthquake load duration.

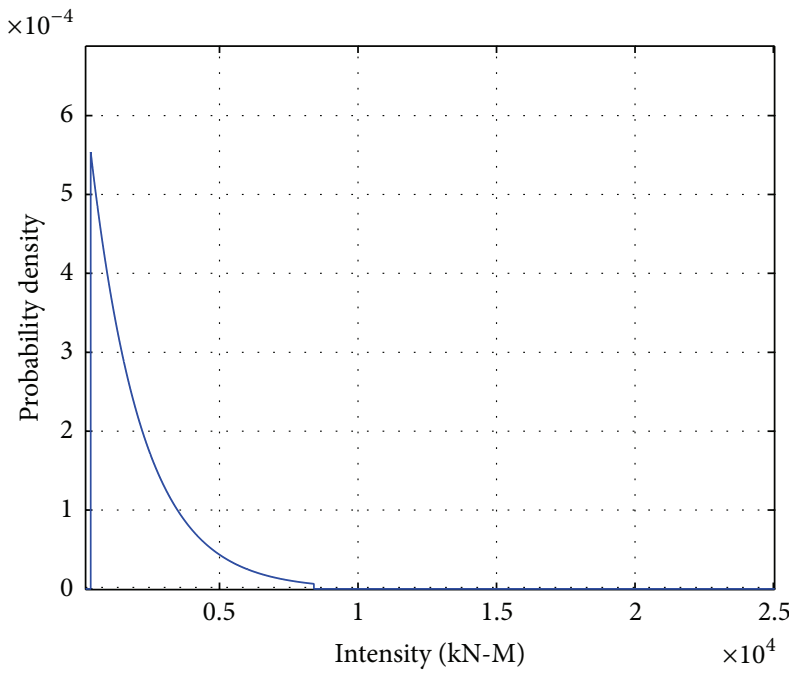

(a)

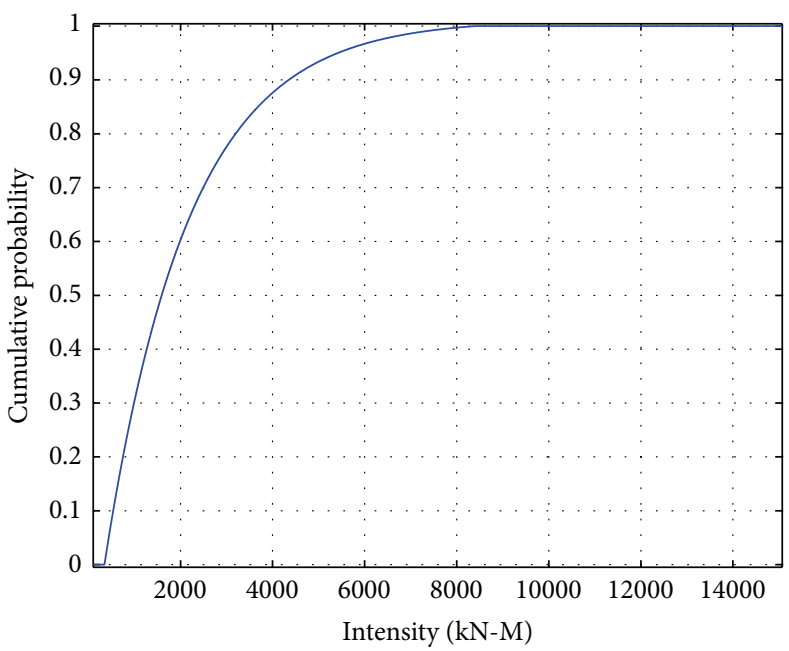

(b)

FIGURE 12: Probability curves for earthquake load in 100 years.

Example 2. Example 2 illustrates vertical load combinations. Most of the configurations are the same as used in Example 1. The difference is in the maximum number of trucks; namely, the maximum number of trucks on one lane in this example is four. The results are shown in Figures 15, 16, 17, 18, 19, and 20 . Figures 13 and 14 are the results of truck load. Note that in this example the $t$ interval is 10 seconds and $T$ is taken as 100 years.

Figures 15 to 16 show vertical truck load probability curves for varied numbers of trucks and probabilities of passing truck numbers on the bridge, over the interval $t$. From Figure 16, it can be seen that the probability is very low when the maximum number of trucks on one lane is four. Figures 17 and 18 show similar curve shapes with those in Figures 13 and 14, which indicate that there is the same rule in load combinations in both the horizontal and vertical directions. Comparing Figures 17 to 20, though the maximum number of trucks is four, because dead load is combined with truck and earthquake load in the gravity direction, the dead load contributes a substantial portion in vertical load combinations.

\section{Conclusions}

This paper describes a method to combine earthquake load and truck load in the service life of bridges. The following conclusions can be drawn.

(1) Given the more than $70 \%$ seismic areas in China, earthquake load is a main consideration for bridge 


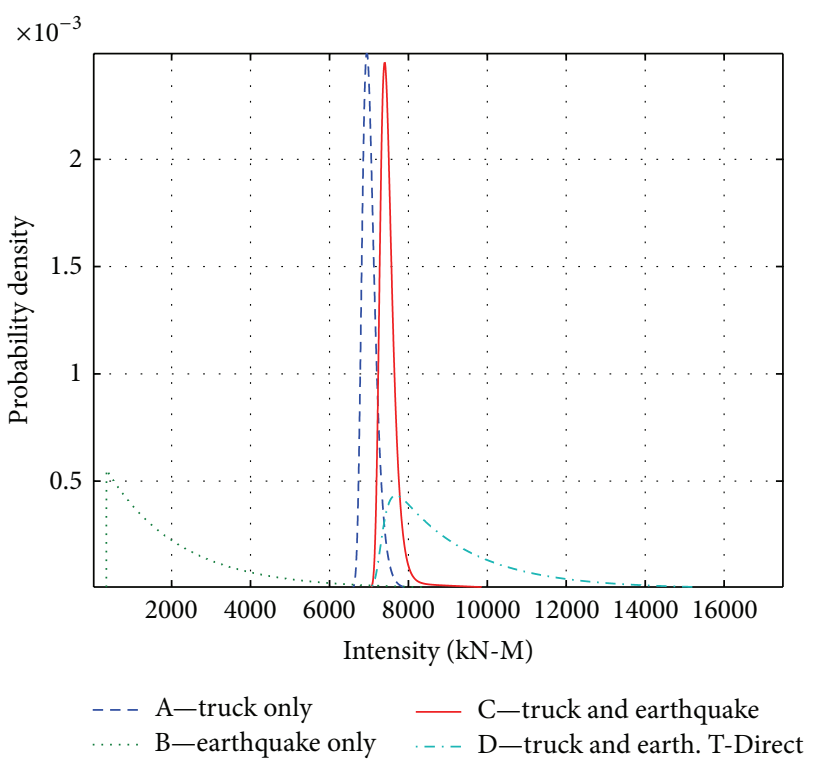

FIGURE 13: Probability density of load combination in 100 years.

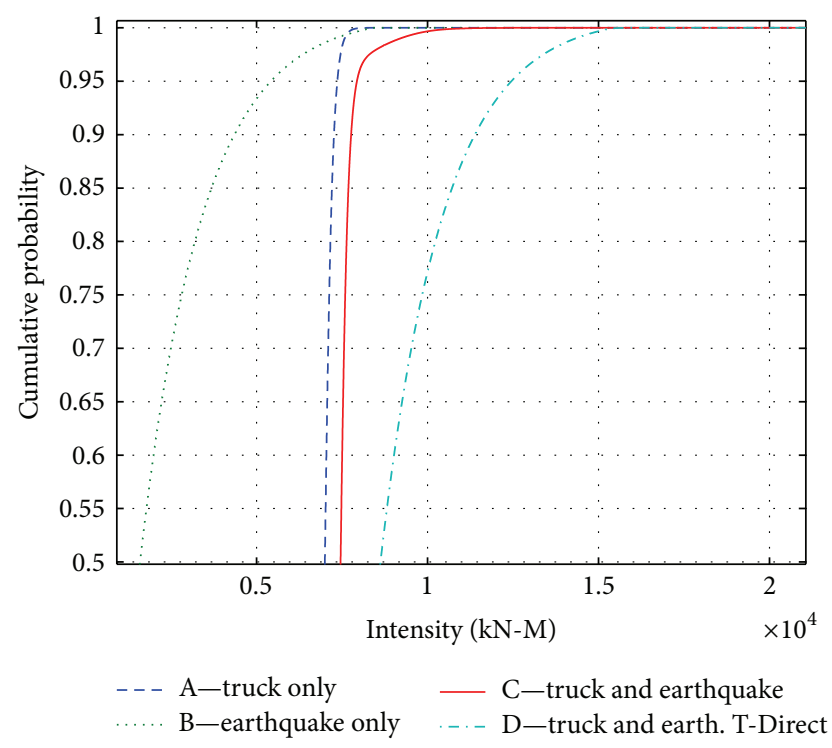

FIGURE 14: Cumulative probability of load combination in 100 years.

design in the southeast coastal areas of China. The earthquake load probability curve is obtained using seismic risk analysis.

(2) Using measured truck load data from BHMS, multimodal characteristics of truck load are analyzed. The truck load density of each truck is obtained by curve fitting. Considering that truck load may consist of varying numbers of trucks, truck load is calculated through traffic analysis.

(3) In this method, the maximum value of combined load is defined as $X_{\max , T}=\max _{T}\left[X_{1}+X_{2}+\cdots X_{n}\right]_{t}$, which means $\left(X_{1}+X_{2}+\cdots X_{n}\right)$ over the interval $t$ is first combined and then the maximum value in the

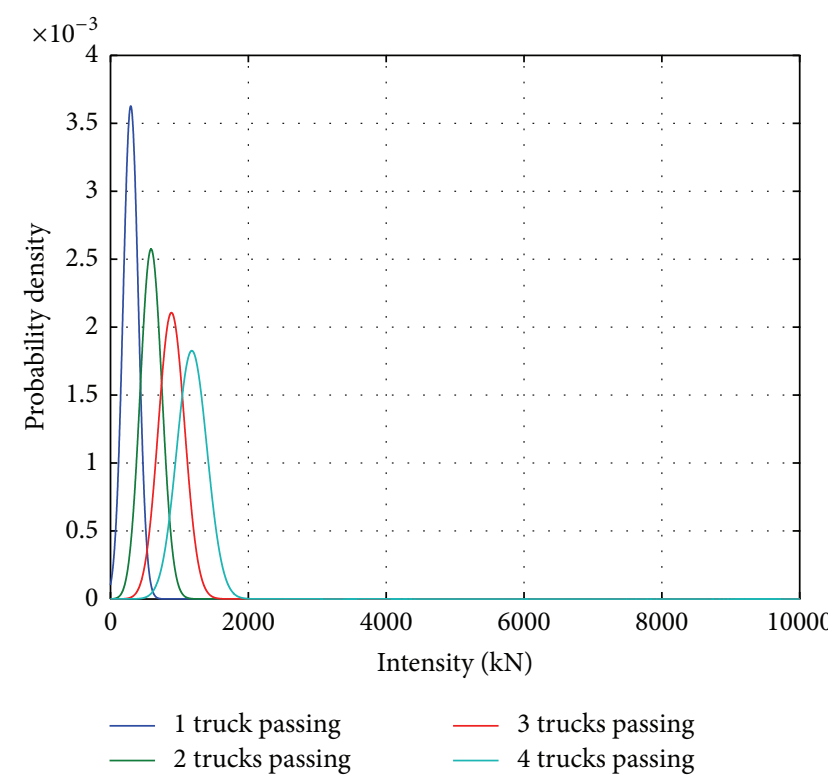

FIGURE 15: Vertical truck load probability density curves for varied number of trucks.

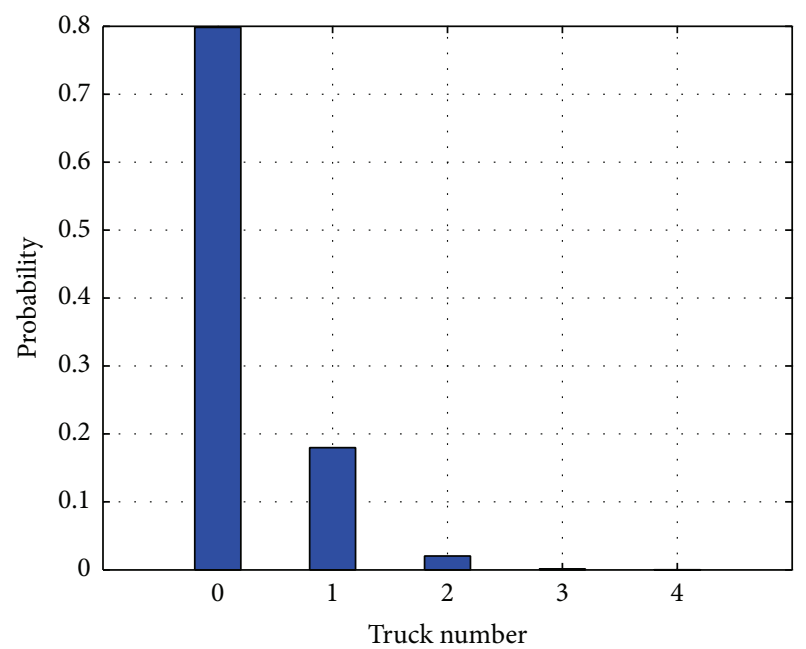

FIGURE 16: Probability of passing truck number simultaneously in $t$ interval on the bridge with maximum number 4 .

bridge service life is determined. $X_{\max , T}$ is based on probability, which covers all the probability combinations of the combined situations. In this method, a Dirac Delta function is introduced to deal with $X$ over a small interval $t$. To demonstrate the methodology intuitively, examples of load combinations in horizontal and vertical directions are provided.

(4) The shape of the earthquake and truck load combination is similar to that of truck load alone, but the curve is displaced to the right, which means the mode and mean value of truck and earthquake load combination in this example is larger than that of truck load alone. This also illustrates that truck load is 


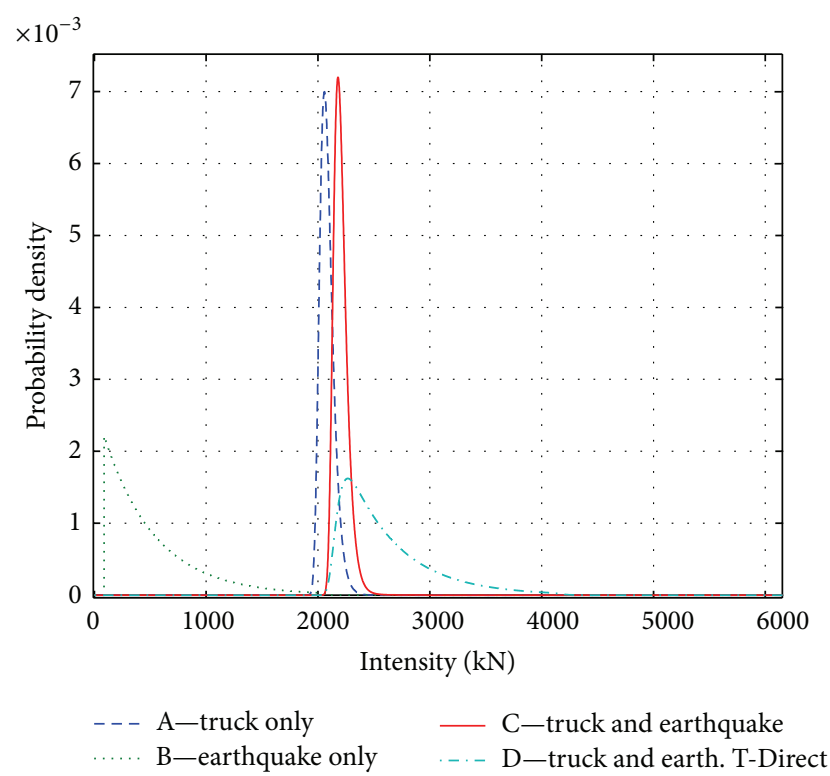

Figure 17: Probability density of vertical load combination in 100 years.

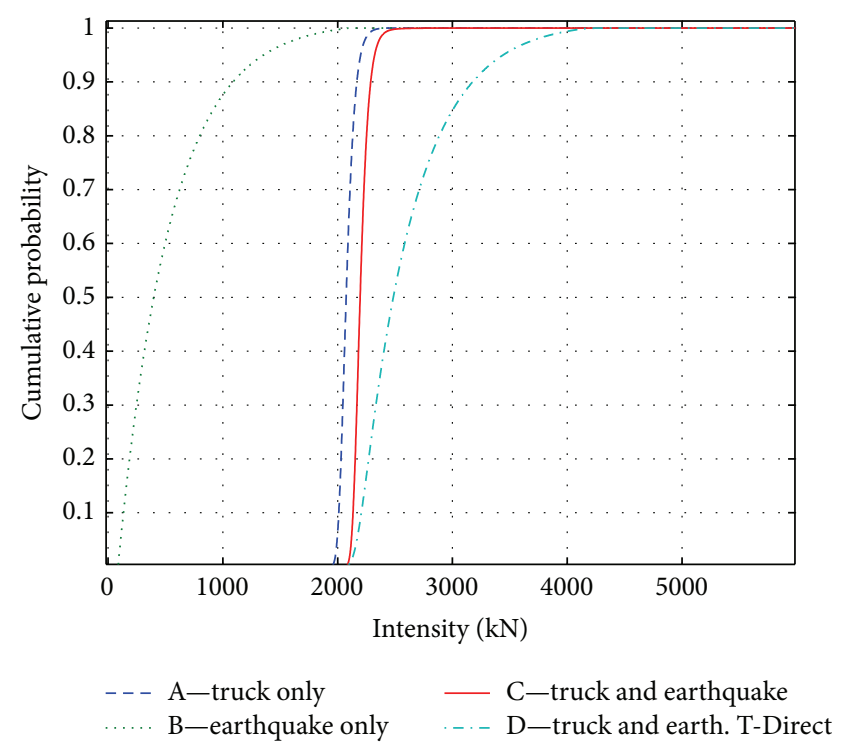

FIGURE 18: Cumulative probability of vertical load combination in 100 years.

more sensitive to bridge design and over most ranges truck load is larger than earthquake load in this area.

(5) The curve from direct load combined over 100 years is further away from the curve obtained using the method in the paper, with the direct combination of truck load and earthquake load over 100 years giving much larger values. It is not suggested that this method be used in bridge design considerations.

(6) Because dead load is combined with truck and earthquake load along the direction of gravity, the dead

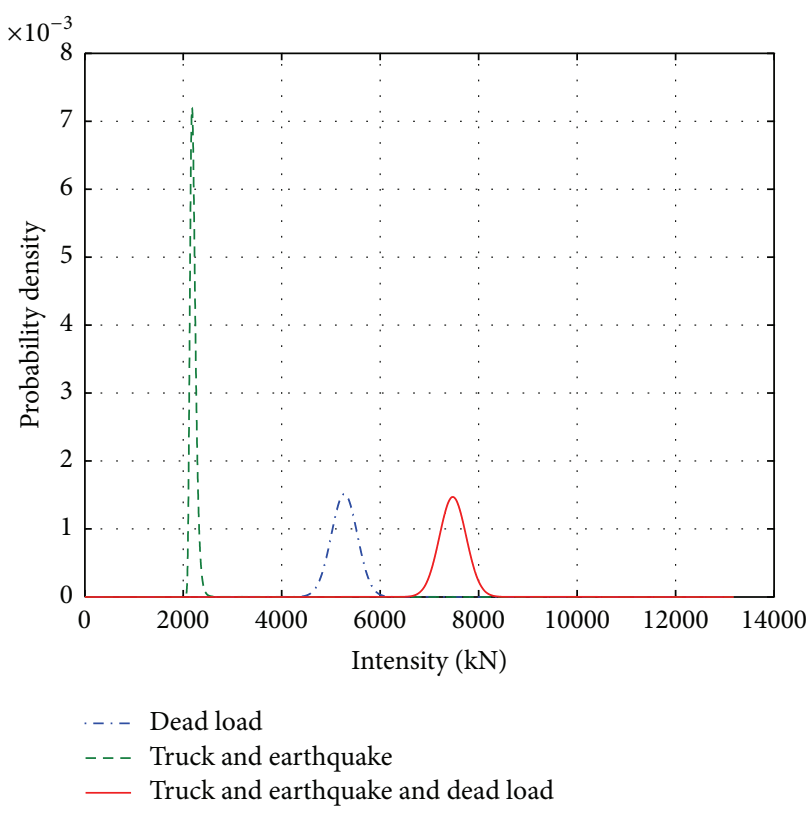

FIGURE 19: Probability density of dead, truck, and earthquake load combination.

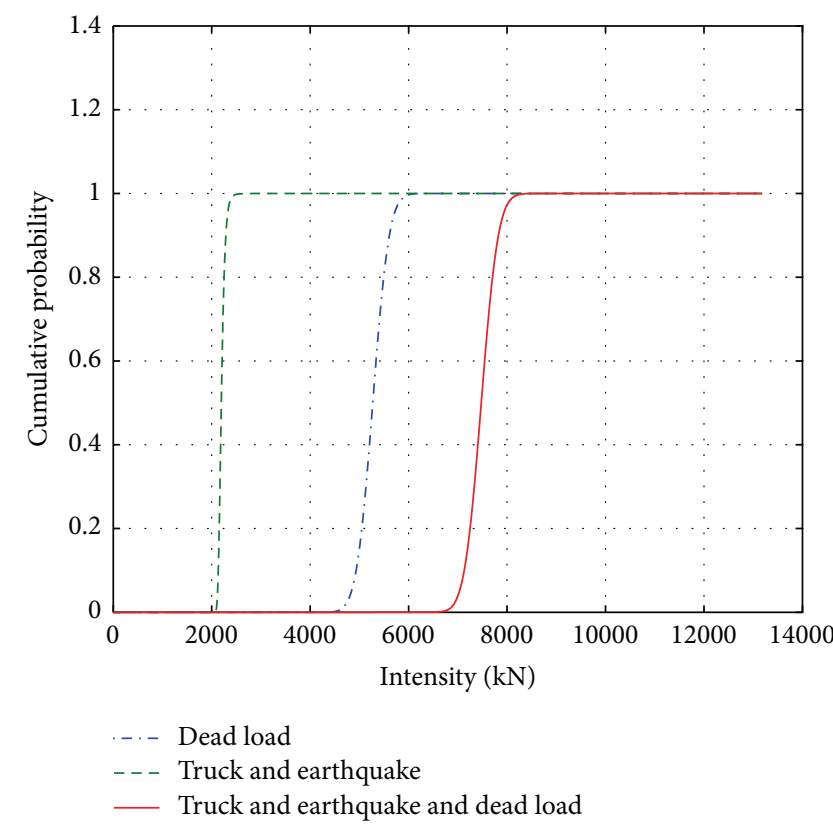

Figure 20: Probability curves of dead, truck, and earthquake load combination.

load contributes a substantial portion in vertical load combinations.

\section{Conflict of Interests}

The authors declare that there is no conflict of interests regarding the publication of this paper. 


\section{Acknowledgments}

This study is jointly funded by Basic Institute Scientific Research Fund (Grant no. 2012A02), the National Natural Science Fund of China (NSFC) (Grant no. 51308510), and Open Fund of State Key Laboratory Breeding Base of Mountain Bridge and Tunnel Engineering (Grant no. CQSLBF-Y1415). The results and conclusions presented in the paper are of the authors and do not necessarily reflect the view of the sponsors.

\section{References}

[1] P. R. China Ministry of Communications, "General code for design of highway bridges and culverts," Tech. Rep. JTG D60200, China Communications Press, Beijing, China, 2004.

[2] T.-H. Yi, H.-N. Li, and M. Gu, "Experimental assessment of high-rate GPS receivers for deformation monitoring of bridge," Measurement: Journal of the International Measurement Confederation, vol. 46, no. 1, pp. 420-432, 2013.

[3] C. J. Turkstra and H. O. Madsen, "Load combinations in codified structural design," Journal of Structural Engineering, vol. 106, no. 12, pp. 2527-2543, 1980.

[4] ACI Publication SP-31, Probabilistic Design of Reinforced Concrete Buildings, American Concrete Institute, Detroit, Mich, USA, 1971.

[5] B. Ellingwood, Development of a Probability Based Load Criterion for American National Standard A58-Building Code Requirements for Minimum Design Loads in Buildings and Other Structures, U.S. Department of Commerce/National Bureau of Standards, 1980.

[6] Y. K. Wen, Development of Reliability-Based Design Criteria for Buildings Under Seismic Load, National Center for Earthquake Engineering Research, Buffalo, NY, USA, 1994.

[7] Y.-K. Wen, "Statistical combination of extreme loads," Journal of Structural Engineering, vol. 103, no. 5, pp. 1079-1093, 1977.

[8] M. Ghosn, F. Moses, and J. Wang, "Design of highway bridges for extreme events," NCHRP 489, Transportation Research Board, National Research Council, Washington, D. C., USA, 2003.

[9] S. E. Hida, "Statistical significance of less common load combinations," Journal of Bridge Engineering, vol. 12, no. 3, pp. 389393, 2007.

[10] Z. Liang and G. C. Lee, "Towards multiple hazard resilient bridges: a methodology for modeling frequent and infrequent time-varying loads-part I, comprehensive reliability and partial failure probabilities," Journal of Earthquake Engineering and Engineering Vibration, vol. 11, no. 3, pp. 293-301, 2012.

[11] Z. Liang and G. C. Lee, "Towards multiple hazard resilient bridges: a methodology for modeling frequent and infrequent time-varying loads Part II, Examples for live and earthquake load effects," Journal of Earthquake Engineering and Engineering Vibration, vol. 11, no. 3, pp. 303-311, 2012.

[12] E. E. Matheu, D. E. Yule, and R. V. Kala, "Determination of standard response spectra and effective peak ground accelerations for seismic design and evaluation," Tech. Rep. no. ERDC/CHL CHETN-VI-41, 2005.

[13] H. N. Li, T. H. Yi, M. Gu, and L. Huo, "Evaluation of earthquakeinduced structural damages by wavelet transform," Progress in Natural Science, vol. 19, no. 4, pp. 461-470, 2009.
[14] B. Chen, Z. W. Chen, Y. Z. Sun, and S. L. Zhao, "Condition assessment on thermal effects of a suspension bridge based on SHM oriented model and data," Mathematical Problems in Engineering, vol. 2013, Article ID 256816, 18 pages, 2013.

[15] T.-H. Yi, H.-N. Li, and M. Gu, "Wavelet based multi-step filtering method for bridge health monitoring using GPS and accelerometer," Smart Structures and Systems, vol. 11, no. 4, pp. 331-348, 2013.

[16] Y. Xia, B. Chen, X. Q. Zhou, and Y. L. Xu, "Field monitoring and numerical analysis of Tsing Ma suspension bridge temperature behavior," Structural Control and Health Monitoring, vol. 20, no. 4, pp. 560-575, 2013.

[17] G. Fu and J. You, "Extrapolation for future maximum load statistics," Journal of Bridge Engineering, vol. 16, no. 4, pp. 527535, 2011.

[18] A. S. Nowak, "Calibration of LRFD bridge design code," NCHRP Report, Transportation Research Board of the National Academies, Washington, DC, USA, 1999.

[19] F. Moses, "Calibration of load factors for LRFD bridge evaluations," NCHRP Report 454, Transportation Research Board of the National Academies, Washington, DC, USA, 2001.

[20] J. Zhao and H. Tabatabai, "Evaluation of a permit vehicle model using weigh-in-motion truck records," Journal of Bridge Engineering, vol. 17, no. 2, pp. 389-392, 2012. 

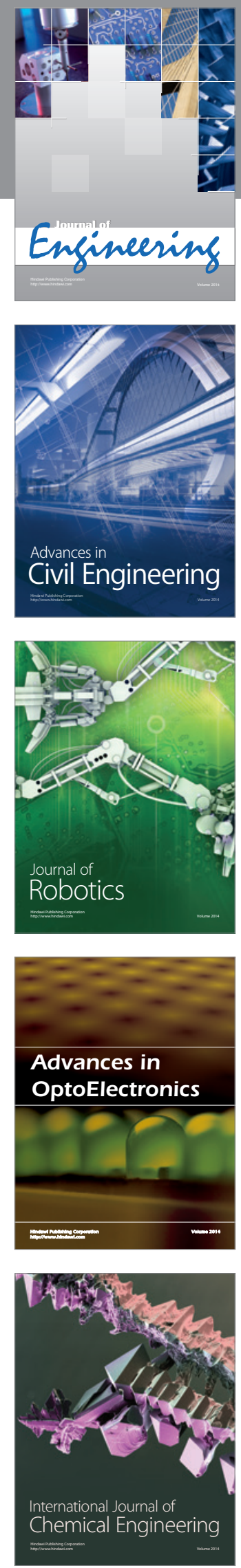

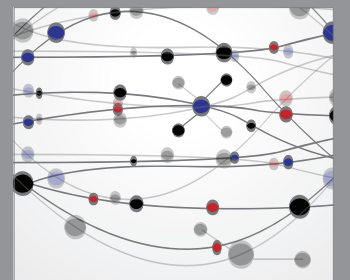

The Scientific World Journal
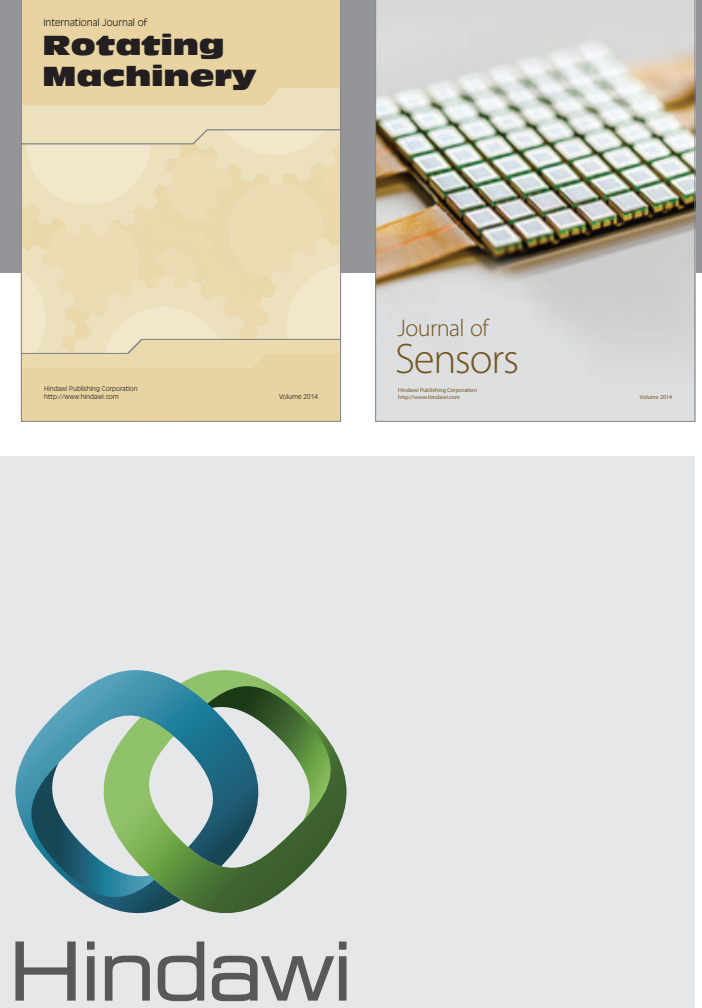

Submit your manuscripts at http://www.hindawi.com
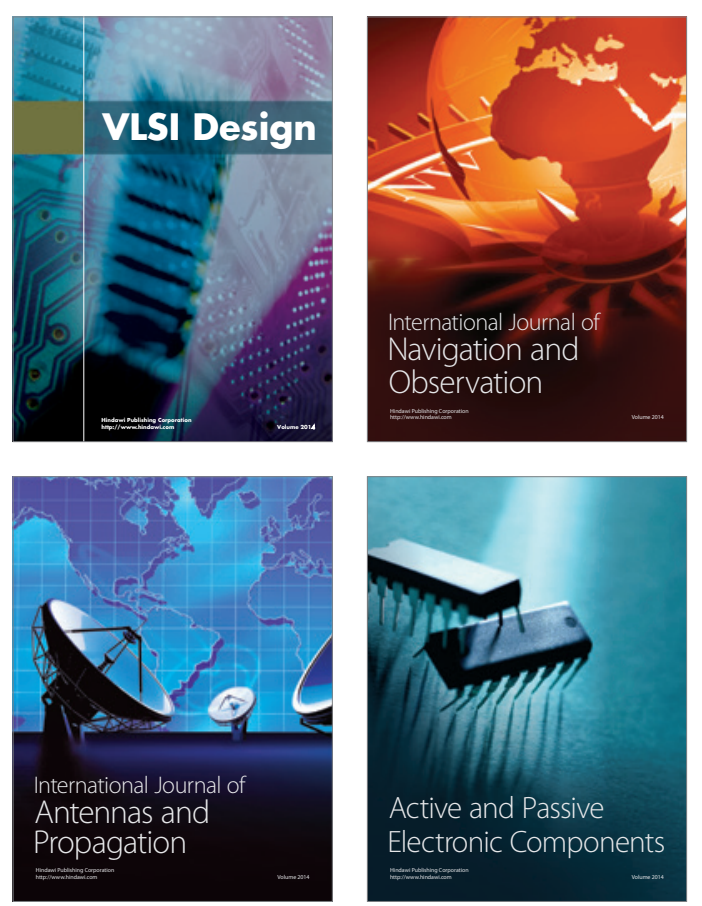
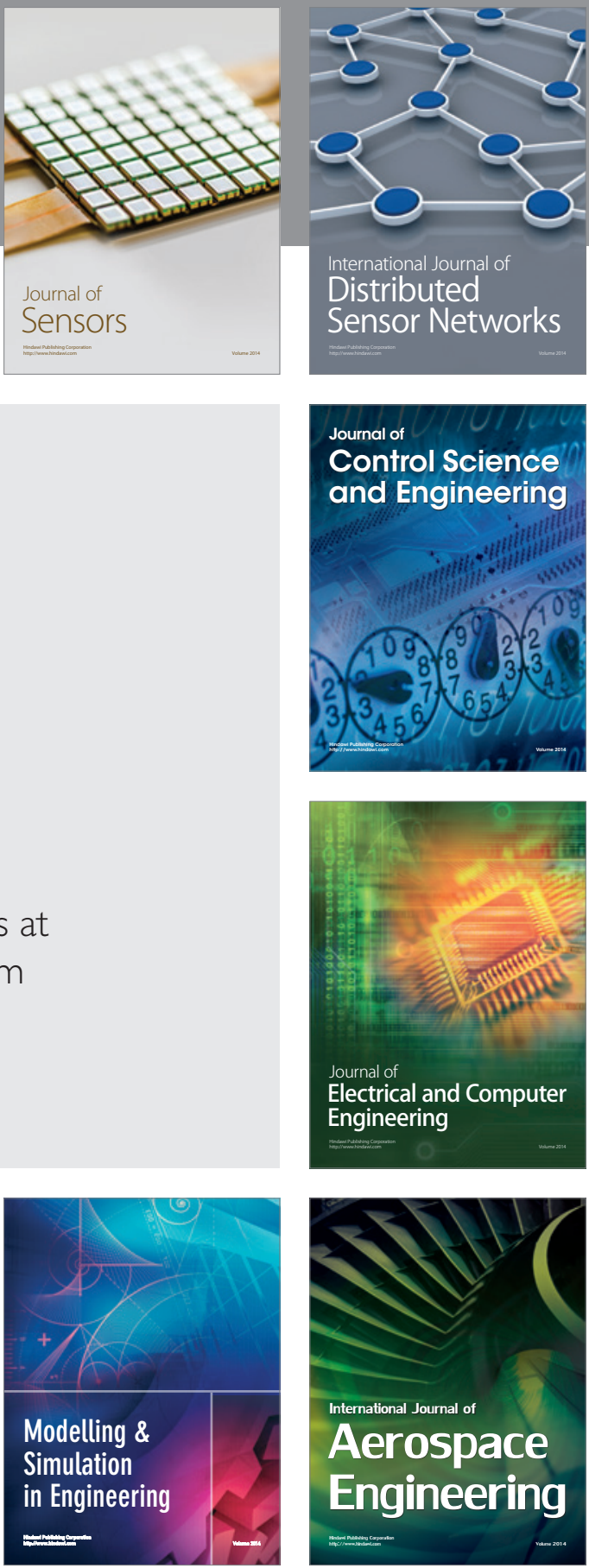

Journal of

Control Science

and Engineering
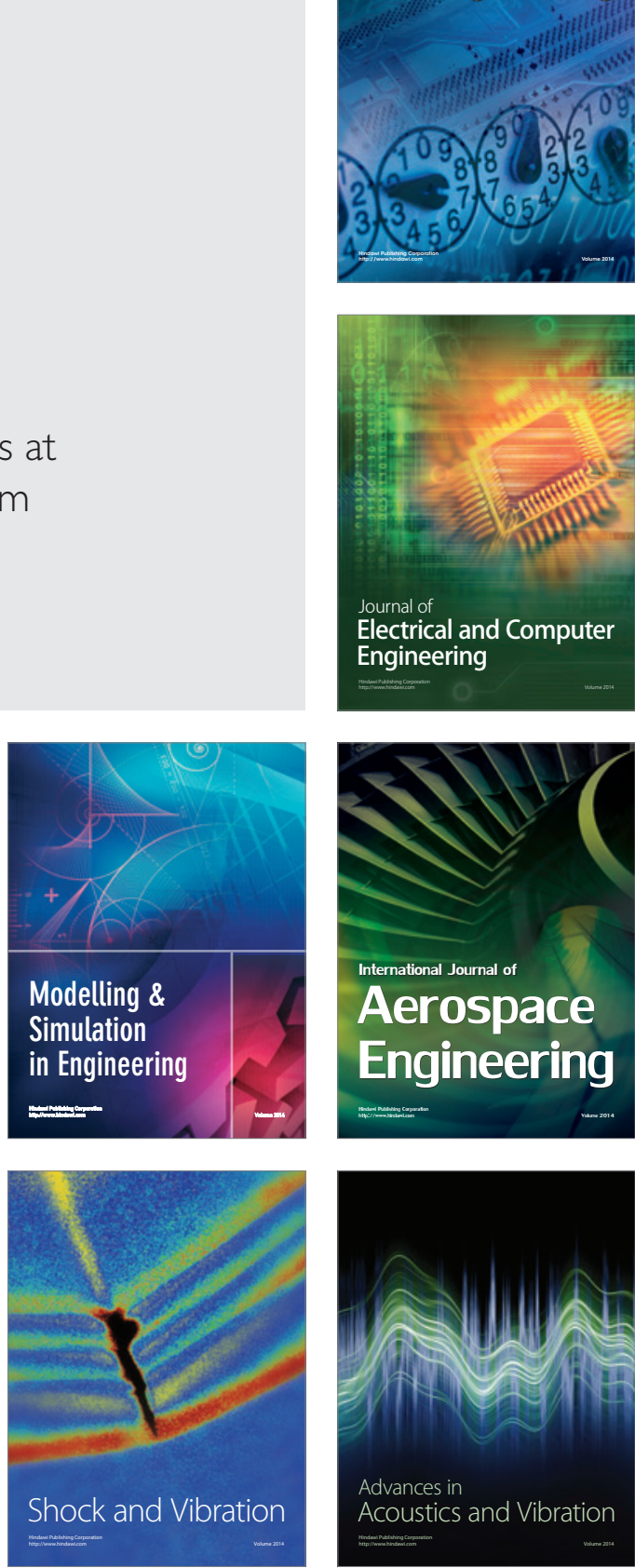